\title{
Clinical study on the influence of motion and other factors on stereotactic radiotherapy in the treatment of adrenal gland tumor
}

This article was published in the following Dove Press journal:

OncoTargets and Therapy

I5 July 2016

Number of times this article has been viewed

\author{
Jingsheng Wang \\ Fengtong $\mathrm{Li}$ \\ Yang Dong \\ Yongchun Song \\ Zhiyong Yuan
}

Department of Radiation Therapy, Tianjin Medical University Cancer Institute and Hospital, National

Clinical Research Center of Cancer, Key Laboratory of Cancer Prevention and Therapy, Tianjin, People's

Republic of China
Correspondence: Fengtong $\mathrm{Li}$

Department of Radiation Therapy, Tianjin Medical University Cancer Institute and Hospital, National Clinical Research Center of Cancer, Key Laboratory of Cancer Prevention and Therapy, Tianjin 300060, People's Republic of China

Tel +862223341405

Fax +86222334 I 405

Email ftong_li@I63.com
Background: The aim of this study was to investigate the adrenal tumor motion law and influence factors in the treatment of adrenal gland tumor and provide a reference value basis for determining the planning target volume margins for therapy.

Materials and methods: The subjects considered in this study were 38 adrenal tumor patients treated with CyberKnife with the placement of 45 gold fiducials. Fiducials were implanted into each adrenal tumor using $\beta$-ultrasonic guidance. Motion amplitudes of gold fiducials were measured with a Philips SLS simulator and motion data in the left-right, anterior-posterior, and cranio-caudal directions were obtained. Multiple linear regression models were used to analyze influencing factors. $t$-Test was used for motion amplitude comparison of different tumor locations along the $z$-axis.

Results: The motion distances were $0.1-0.4 \mathrm{~cm}(0.27 \pm 0.07 \mathrm{~cm}), 0.1-0.5 \mathrm{~cm}(0.31 \pm 0.11 \mathrm{~cm})$, and $0.5-1.2 \mathrm{~cm}(0.87 \pm 0.21 \mathrm{~cm})$ along the $x$-, $y$-, and $z$-axes, respectively. Motion amplitude along the $z$-axis may be affected by tumor location, but movement along the other axes was not affected by age, height, body mass, location, and size.

Conclusion: The maximum motion distance was along the $z$-axis. Therefore, this should be the main consideration when defining the planning target volume safety margin. Due to the proximity of the liver, adrenal gland tumor motion amplitude was smaller on the right than the left. This study analyzed adrenal tumor motion amplitude data to evaluate how motion and other factors influence the treatment of adrenal tumor with a goal of providing a reference for stereotactic radiotherapy boundary determination.

Keywords: adrenal gland, gold fiducial, law of motion, CyberKnife, influence factors

\section{Introduction}

The adrenal gland is an important endocrine organ. It is located above the kidney, encapsulated by the renal fascia and fatty tissue. The left adrenal gland is half-moonshaped and the right is triangular. ${ }^{1-3}$ The adrenal gland is composed of an outer cortex and an inner medulla. Adrenal metastases rank fourth among hematogenous tumor metastases, with the most common primaries being lung, breast, stomach, liver, and pancreatic cancers. ${ }^{4-6}$

Adrenal gland tumors are treated surgically or with radiation therapy. ${ }^{7} \mathrm{With}$ imageguided, precision-positioning technology and other advances in radiotherapy allowing high-precision, high-dose, noninvasive treatment with shorter split times, stereotactic radiotherapy is increasingly being recognized. During the process of stereotactic radiotherapy, adrenal movement is affected by breathing. Uncertainty regarding the degree of the resulting adrenal displacement greatly impacts the ability to accurately direct 
radiotherapy. ${ }^{8-11}$ This study analyzes adrenal tumor motion amplitude data to allow a better understanding of how motion and other factors influence the treatment of adrenal tumor in order to provide a reference for stereotactic radiotherapy boundary determination.

\section{Materials and methods Patients}

Thirty-eight adrenal gland tumor patients (30 males, eight females) received CyberKnife treatment between August 2006 and November 2015 at Tianjin Medical University Cancer Hospital (Tianjin, People's Republic of China). The age range was $27-85$ years, with a median age of 55 . Height range was $162-176 \mathrm{~cm}$, with a median value of $169.5 \mathrm{~cm}$. Body weight ranged from 52 to $85 \mathrm{~kg}$, median $69 \mathrm{~kg}$. The number of adrenal gland tumors was 40 , including 18 in the left adrenal and 22 in the right. Two patients had bilateral adrenal tumors. Tumors ranged in size from 2.59 to $120.42 \mathrm{~cm}^{3}$, with the median value of $41.29 \mathrm{~cm}^{3}$. The $x$-axis direction was defined as left to right, the $y$-axis as anterior to posterior, and the $z$-axis as superior to inferior. The study was approved by the Tianjin Cancer Institute and Hospital ethics committee. All patients consented to participate in the study and allow their information to be stored in the hospital database for use in research. Furthermore, at the time of patient follow-up, in order to document the process, a doctor, a staff member of the hospital ethics committee, and a staff member from the medical record department were simultaneously required.

\section{Equipment and measurement methods}

Thirty-eight patients with adrenal tumors were treated. Gold fiducials (length $5 \mathrm{~mm}$, diameter $0.8 \mathrm{~mm}$ ) were inserted into the tumors using $\beta$-ultrasonic wave technology (LOGIQ E9, GE Healthcare UK Ltd, Little Chalfont, UK). The total number of gold fiducials placed was 45 . When two gold fiducials were implanted into the same tumor, the spacing between them was required to be $>2 \mathrm{~cm}$. After 1 week, a Philips Brilliance computed tomography (CT) 16-slice spiral simulator was used to perform continuous, uninterrupted abdominal CT scanning of the patients. Parameters were defined as a tube voltage of $120 \mathrm{kV}$, a tube current of $400 \mathrm{~mA}$, and a tube thickness of $1.5 \mathrm{~mm}$. Scan range was from the center of the gold fiducials, respectively, spanning $15 \mathrm{~cm}$ in each direction. After confirmation of the accuracy of positioning of the fiducials, patients were positioned supine on the Philips SLS simulator and they received training in releasing abdominal pressure and breathing quietly. The simulation machine voltage range was $70-90 \mathrm{kV}$, with a current of 1-2 mA. After observation of four to six respiratory cycles, the motion distance between gold fiducials along each axis was measured. During quiet breathing, the maximum motion amplitude of gold fiducials was recorded as the motion amplitude in that direction, accurate to $\mathrm{mm}$. When the large gantry angle of the Philips SLS simulator was $0^{\circ}$, the motion distance of gold fiducials in the coronal, $z$ and $x$ axes, was measured. When the large gantry angle was $+90^{\circ}$, the motion distance of gold fiducials in the vertical plane, or $y$-axis, was measured.

\section{Statistical methods}

SPSS 13.0 software was used for statistical analysis. Multiple linear regression analysis was performed, taking into account age, height, body mass, tumor location (left or right adrenal gland), tumor size, and other factors affecting adrenal tumor motion amplitude in the three directions studied. The mean \pm standard deviation $(\mathrm{x} \pm \mathrm{s})$ represented motion amplitude. Student's $t$-Test was used for comparison of the five factors studied. $P<0.05$ was considered statistically significant.

\section{Result}

Implantation of gold fiducials, using $\beta$-ultrasound guidance (Figure 1), was successfully achieved in all cases, as confirmed by CT scan (Figure 2). Motion amplitude of the gold fiducials, as measured with a Philips SLS simulator, was found to be consistent with breathing patterns. The end-expiratory and end-inspiratory phases of respiration were responsible for the majority of motion of gold fiducials witnessed in all three planes (Figure 3).

\section{Measurement of the results of gold fiducial motion}

Adrenal gold fiducial motion distance in the three planes measured was as follows: $x$-axis, $0.27 \pm 0.07 \mathrm{~cm}(0.1-0.4 \mathrm{~cm})$;

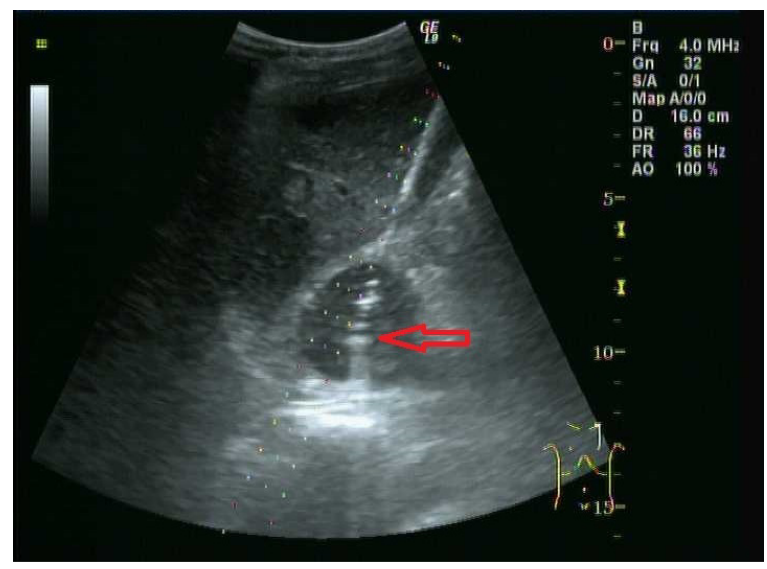

Figure I $\beta$-Ultrasonic wave technology images.

Note: Red arrow shows the gold fiducial which was implanted into the left adrenal tumor. 


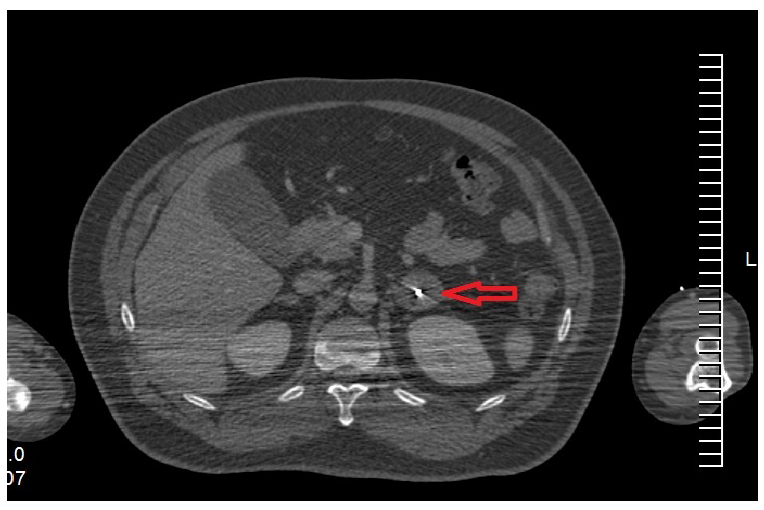

Figure 2 Computed tomography images.

Note: Red arrow shows the gold fiducial was implanted into the left adrenal tumor.

$y$-axis, $0.31 \pm 0.11 \mathrm{~cm}(0.1-0.5 \mathrm{~cm})$; and $z$-axis, $0.87 \pm 0.21 \mathrm{~cm}$ $(0.5-1.2 \mathrm{~cm})$. Tables $1-3$, respectively, illustrate the gold fiducial motion distance along the $x$-, $y$-, and $z$-axes in relation to the dependent variables of age, height, body mass, tumor location (left or right adrenal gland), and tumor size as a multivariate regression analysis (test data were normally distributed). The regression model is presented as follows:

$$
\begin{gathered}
y_{1}=-0.02 x_{4} \\
y_{2}=0.001 x_{1}-0.008 x_{2}+0.002 x_{3}-0.055 x_{4} \\
y_{3}=0.006 x_{1}+0.003 x_{2}-0.003 x_{3}-0.197 x_{4}+0.001 x_{5}
\end{gathered}
$$

where $y_{1}, y_{2}$, and $y_{3}$ represent the motion distance of the gold fiducials along the $x$-, $y$-, and $z$-axes, respectively, and $x_{1}, x_{2}$, $x_{3}, x_{4}$, and $x_{5}$ represent the dependent variables of age, height, body mass, tumor location, and tumor size $(\alpha=0.05)$, respectively. The results show that the tumor's $z$-axis mobility may be affected by tumor location $(P=0.002)$, whereas movement along the other axes was not affected by any of the other variables (Tables 1-3).

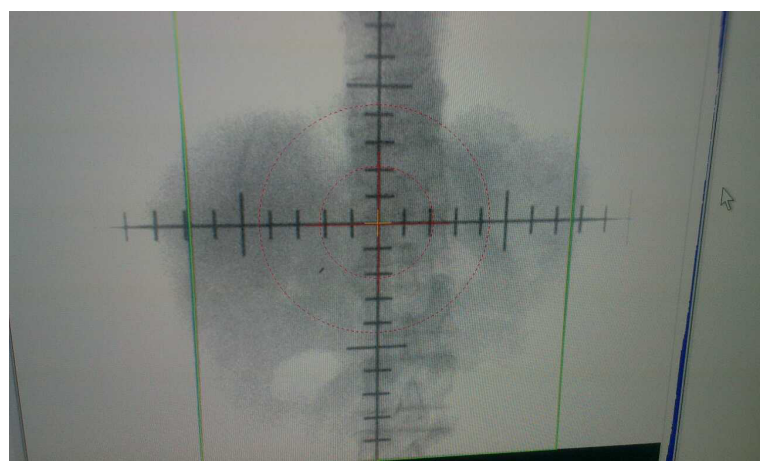

Figure 3 Using the Philips SLS simulator observation motion range of gold fiducials.

Note: The line represents the maximum displacement motion, and the straight line spacing represents the gold fiducial motion amplitude.
Table I Multivariate linear regression analysis of the $x$-axis

\begin{tabular}{llll}
\hline Factor & $\boldsymbol{\beta}$ & SE & $\boldsymbol{P}$-value \\
\hline Age & $<0.001$ & $<0.001$ & 0.960 \\
Height & $<0.001$ & 0.010 & 0.530 \\
Body weight & $<0.001$ & $<0.001$ & 0.840 \\
Lesion location & -0.020 & 0.030 & 0.390 \\
Lesion size & $<0.001$ & $<0.001$ & 0.580 \\
\hline
\end{tabular}

Abbreviation: SE, standard error.

\section{Comparison of amplitude of motion of left- versus right-sided tumors along the z-axis}

The amplitude of motion of left and right adrenal tumors along the $z$-axis was $0.99 \pm 0.22$ and $0.79 \pm 0.16 \mathrm{~cm}$, respectively. The amplitude of motion of right adrenal tumors was smaller than that of left-sided tumors $(t=4.08, P=0.000)$.

\section{Discussion}

Because of adrenal tumors' proximity to the stomach, duodenum, liver, kidney, and other vital organs, it has been difficult to achieve focused adrenal irradiation in sufficient dosage. ${ }^{12}$ The appearance of CyberKnife and the ability to use real-time image guidance have increased our ability to treat adrenal tumors with more accurately dosed irradiation, so the target delineation and outside range become very important. ${ }^{13,14}$

Large interpatient variations in adrenal motion occur during uncoached respiration, indicating a role of respiratory coaching during 4D CT imaging and treatment delivery. ${ }^{15}$ The symptomatic complications following ultrasoundguided percutaneous implantation of fiducial markers are relatively low. However, careful consideration of the relatively higher rates of migration and discrimination failure is needed when performing ultrasound-guided percutaneous implantation of fiducial markers. ${ }^{16-18}$ The absolute change in mean tumor position from first to third 10-minute blocks was $>5 \mathrm{~mm}$ in $13 \%$ and $7 \%$ of lung and pancreas cases, respectively. Significantly increasing tumor position prediction model error (mean \pm standard deviation rates of change of $1.6 \pm 2.5 \mathrm{~mm}$ per 10 minutes) over 30 minutes indicated

Table 2 Multivariate linear regression analysis of the $y$-axis

\begin{tabular}{llll}
\hline Factor & $\boldsymbol{\beta}$ & SE & $\boldsymbol{P}$-value \\
\hline Age & 0.001 & 0.002 & 0.632 \\
Height & -0.008 & 0.008 & 0.344 \\
Body weight & 0.002 & 0.003 & 0.592 \\
Lesion location & -0.055 & 0.037 & 0.146 \\
Lesion size & $<0.001$ & 0.001 & 0.516 \\
\hline
\end{tabular}

Abbreviation: SE, standard error. 
Table 3 Multivariate linear regression analysis of the $z$-axis

\begin{tabular}{llll}
\hline Factor & $\boldsymbol{\beta}$ & $\mathbf{S E}$ & $\boldsymbol{P}$-value \\
\hline Age & 0.006 & 0.003 & 0.830 \\
Height & 0.003 & 0.013 & 0.806 \\
Body weight & -0.003 & 0.006 & 0.562 \\
Lesion location & -0.197 & 0.059 & 0.002 \\
Lesion size & 0.001 & 0.001 & 0.527 \\
\hline
\end{tabular}

Abbreviation: SE, standard error.

tumor-surrogate relationship changes in 63\% of fractions. ${ }^{19}$ Imaging data and medical records of 28 patients with 40 liver metastases treated with stereotactic body radiotherapy were reviewed. Tumor size, CT attenuation coefficient, and contrast enhancement of lesions were evaluated up to 2 years post stereotactic body radiotherapy. Rates of local control, progression-free survival, time to progression, and overall survival according to the combined criteria response according to change in size (RECIST) were estimated. ${ }^{20} \mathrm{Xie}$ et $\mathrm{al}^{21}$ report the characteristics of prostate motion as tracked by the stereoscopic X-ray images of the implanted fiducials during hypofractionated radiotherapy with CyberKnife.

Sazawa's study ${ }^{22}$ of therapy for adrenal metastasis of prostate tumor showed that, in patients not undergoing laparoscopic adrenalectomy, real-time tracking radiotherapy using an implanted colloidal gold marker was an effective alternative to surgery. Katoh observed nine cases of adrenal tumor patients implanted with ten gold fiducials using real-time tumor tracking radiotherapy. The average motion amplitude of gold fiducials in the supine position along the $x, y$, and $z$ axes were $0.34 \pm 0.29 \mathrm{~cm}, 0.06-0.91 \mathrm{~cm} ; 0.99-0.98 \mathrm{~cm}, 0.11-2.71 \mathrm{~cm}$; and $0.14-0.52 \mathrm{~cm}, 0.17-2.66 \mathrm{~cm}$, respectively. The average motion amplitudes of gold fiducials in the prone position along the $x, y$, and $z$ axes were $0.61 \pm 0.44 \mathrm{~cm}, 0.23-1.44 \mathrm{~cm} ; 1.11 \pm 0.71 \mathrm{~cm}$, $0.35-2.52 \mathrm{~cm}$; and $0.70 \pm 0.35 \mathrm{~cm}, 0.39-1.25 \mathrm{~cm}$, respectively. In the supine and prone positions, the absolute motion amplitudes of gold fiducials were not significant. ${ }^{23}$

Because gold fiducials have been implanted into the adrenal tumors, this method accurately represents the real circumstances seen with irradiation. The results showed that motion amplitude of adrenal tumors was independent of age, height, weight, and tumor size. Motion distance of gold fiducials within the tumors was significantly larger along the $z$-axis than along the $x$ - or $y$-axis. Due to the limitations posed by the presence of the liver, motion amplitude of right adrenal gland tumors along the $z$-axis was smaller than in left-sided tumors.

\section{Conclusion}

The study sample size and sample selection scope was small making clinical parameters and statistics imperfect. Although not enough to reflect the general motion laws of adrenal gland tumors, the results provided certain value in determining the planning target volume margins for treatment. The motion amplitude of adrenal gland tumors was affected by respiration, and motion distance was maximal along the $z$-axis. Due to restrictions posed by the presence of the liver, the motion amplitude of right adrenal gland tumors along the $z$-axis was smaller than in left-sided tumors. Therefore, in the implementation of stereotactic radiotherapy, the main consideration during planning should be to target tumor motion along the $z$-axis. Reduction of tumor motion during radiotherapy can be accomplished using the method of breath control, thereby improving radiation within a smaller, more directed field. The results achieved illustrate improved local tumor control rates and reduced normal tissue complications.

\section{Acknowledgments}

The authors thank the staff of the Tianjin Cancer Hospital and all patients who were associated with this study.

\section{Disclosure}

The authors report no conflicts of interest in this work.

\section{References}

1. Yasaka K, Gonoi W, Akai H, et al. Differentiation of adrenal tumors in patients with hepatocellular carcinoma: adrenal adenoma versus metastasis. Eur J Radiol. 2013;82(8):1213-1218.

2. Hahner S, Kreissl MC, Fassnacht M, et al. Functional characterization of adrenal tumors using [ $\left.{ }^{123} \mathrm{I}\right] \mathrm{IMTO}-\mathrm{SPECT} / \mathrm{CT}$. J Clin Endocrinol Metab. 2013;98(4):1508-1518.

3. Mercier O, Fadel E, de Perrot M, et al. Surgical treatment of solitary adrenal metastasis from non-small cell lung cancer. $J$ Thorac Cardiovasc Surg. 2005;130(1):136-140.

4. Brunt LM, Doherty GM, Norton JA, Soper NJ, Quasebarth MA, Moley JF. Laparoscopic adrenalectomy compared to open adrenalectomy for benign adrenal neoplasms. J Am Coll Surg. 1996;183(1):1-10.

5. Kim SH, Brennan MF, Russo P, Burt ME, Coit DG. The role of surgery in the treatment of clinically isolated adrenal metastasis. Cancer. 1998;82(2):389-394.

6. Higashiyama M, Doi O, Kodama K, Yokouchi H, Imaoka S, Koyama H. Surgical treatment of adrenal metastasis following pulmonary resection for lung cancer: comparison of adrenalectomy with palliative therapy. Int Surg. 1994;79(2):124-129.

7. Sebag F, Calzolari F, Harding J, Sierra M, Palazzo FF, Henry JF. Isolated adrenal metastasis: the role of laparoscopic surgery. World J Surg. 2006; 30(5):888-892.

8. Zeng ZC, Tang ZY, Fan J, et al. Radiation therapy for adrenal gland metastases from hepatocellular carcinoma. Jpn J Clin Oncol. 2005; 35(2):61-67.

9. Soffen EM, Solin LJ, Rubenstein JH, Hanks GE. Palliative radiotherapy for symptomatic adrenal metastases. Cancer. 1990;65(6):1318-1320.

10. Mallarajapatna GJ, Susheela SP, Kallur KG, et al. Technical note: image guided internal fiducial placement for stereotactic radiosurgery (CyberKnife). Indian J Radiol Imaging. 2011;21(1):3-5.

11. De Salles AA, Gorgulho AA, Pereira JL, McLaughlin N. Intracranial stereotactic radiosurgery: concepts and techniques. Neurosurg Clin N Am. 2013;24(4):491-498. 
12. Attenello FJ, Lee B, Yu C, Liu CY, Apuzzo ML. Supplementing the neurosurgical virtuoso: evolution of automation from mythology to operating room adjunct. World Neurosurg. 2014;81(5-6):719-729.

13. Shirato H, Shimizu S, Kunieda T, et al. Physical aspects of a real-time tumor tracking system for gated radiotherapy. Int J Radiat Oncol Biol Phys. 2000;48(4):1187-1195.

14. van Sörnsen de Koste JR, Senan S, Kleynen CE, Slotman BJ, Lagerwaard FJ. Renal mobility during uncoached quiet respiration: an analysis of 4DCT scans. Int J Radiat Oncol Biol Phys. 2006;64(3): 799-803.

15. Sotiropoulou E, Stathochristopoulou I, Stathopoulos K, Verigos K, Salvaras N, Thanos L. CT-guided fiducial placement for cyberknife stereotactic radiosurgery: an initial experience. Cardiovasc Intervent Radiol. 2010;33(3):586-589.

16. Kim JH, Hong SS, Kim JH, et al. Safety and efficacy of ultrasoundguided fiducial marker implantation for CyberKnife radiation therapy. Korean J Radiol. 2012;13(3):307-313.

17. Pishvaian AC, Collins B, Gagnon G, Ahlawat S, Haddad NG. EUSguided fiducial placement for CyberKnife radiotherapy of mediastinal and abdominal malignancies. Gastrointest Endosc. 2006;64(3):412-417.
18. Trumm CG, Häussler SM, Muacevic A, et al. CT fluoroscopy-guided percutaneous fiducial marker placement for CyberKnife stereotactic radiosurgery: technical results and complications in 222 consecutive procedures. J Vasc Interv Radiol. 2014;25(5):760-768.

19. Malinowski K, McAvoy TJ, George R, Dietrich S, D’Souza WD. Incidence of changes in respiration-induced tumor motion and its relationship with respiratory surrogates during individual treatment fractions. Int J Radiat Oncol Biol Phys. 2012;82(5):1665-1673.

20. Jarraya H, Mirabel X, Taieb S, et al. Image-based response assessment of liver metastases following stereotactic body radiotherapy with respiratory tracking. Radiat Oncol. 2013;8:24.

21. Xie Y, Djajaputra D, King CR, Hossain S, Ma L, Xing L. Intrafractional motion of the prostate during hypofractionated radiotherapy. Int J Radiat Oncol Biol Phys. 2008;72(1):236-246.

22. Sazawa A, Shinohara N, Harabayashi T, Abe T, Shirato H, Nonomura K. Alternative approach in the treatment of adrenal metastasis with a realtime tracking radiotherapy in patients with hormone refractory prostate cancer. Int J Urol. 2009;16(4):410-412.

23. Katoh N, Onimaru R, Sakuhara Y, et al. Real-time tumor-tracking radiotherapy for adrenal tumors. Radiother Oncol. 2008;87(3):418-424.

\section{Publish your work in this journal}

OncoTargets and Therapy is an international, peer-reviewed, open access journal focusing on the pathological basis of all cancers, potential targets for therapy and treatment protocols employed to improve the management of cancer patients. The journal also focuses on the impact of management programs and new therapeutic agents and protocols on

\section{Dovepress}

patient perspectives such as quality of life, adherence and satisfaction. The manuscript management system is completely online and includes a very quick and fair peer-review system, which is all easy to use. Visit http://www.dovepress.com/testimonials.php to read real quotes from published authors. 